\title{
Sontag, historiadora
}

\section{Sontag, Historian}

\author{
Camila Gatica / Rafael Gaune \\ Instituto de Historia \\ Pontificia Universidad Católica de Chile \\ cgatica1@uc.cl / rgaune@uc.cl
}

\section{Resumen}

El artículo propone que es posible establecer diálogos apócrifos entre la historiografía del siglo xx y los libros Contra la interpretación y Sobre la fotografía de Susan Sontag, así como es posible construir analogías con el trabajo del historiador. Se plantea, por un lado, que los autores que Sontag analiza y clasifica en Contra la interpretación se modelan como los documentos que le permiten al historiador ingresar al pasado para ordenarlo e interpretarlo y, por otro, que Sobre la fotografía es una propuesta metodológica de cómo entender los vínculos entre memoria, imagen, clasificación y realidad.

Palabras clave: Susan Sontag, historiografía, oficio del historiador, clasificación.

\section{Abstract}

The article states that we can establish apocryphal dialogues between twentieth century historiography and the books Against Interpretation and On Photography, as well as analogies with history as a discipline. It suggests that Sontag analyzes and classifies in Against Interpretation are modeled just like the documents that allow a historian to establish a dialogue with the past, in order to organize and interpret it; and that On Photography is a methodological proposal of how to understand the links between memory, image, classification and reality.

Keywords: Susan Sontag, historiography, historian's trade, classification. 


\section{Partir por una coma}

"Sontag, historiadora", es una afirmación polémica, un título riesgoso, una frase amplia, quizás inabordable, tal vez sin respuesta. Es también una frase engañosa y, por qué no decirlo, facilista, un tanto obvia si es formulada por dos historiadores que escriben un artículo sobre Susan Sontag. Sin embargo, mientras redactábamos estas páginas, leímos la introducción del último libro de Carlo Ginzburg, Nondimanco. Machiavelli, Pascal, sobre la casuística medieval en el pensador toscano y el tratamiento polémico del casuismo en el francés jansenista, que nos ofreció una importante pista. Advertimos, de antemano, que no tiene vinculación alguna con el contenido del libro, sino con algo que Ginzburg hace explícito: el uso de la coma entre los dos autores en el subtítulo. En las primeras líneas expone: "Antes que todo, el subtítulo: Machiavelli, Pascal. ¿Por qué la coma? La coma es un signo ambiguo: puede indicar una conjunción o una disyunción. En este caso, ambas". ${ }^{1}$ Esa coma une y separa a Maquiavelo y Pascal a través de la casuística. En nuestro caso, esa coma separa y une a Sontag de las formas de hacer historia y de los historiadores. Esto, sin duda, merece una explicación más detallada.

Sabemos que para Susan Sontag los historiadores no están presentes en su amplio catálogo de autores estudiados, queridos e idealizados. Ahí se encuentra, por ejemplo, su precoz lectura de Thomas Mann en California, o su desmedida admiración por la escritura de Walter Benjamin. Sus densos ensayos sobre Cesare Pavese, György Lukács, Claude Levi-Strauss, Simone Weil, o su conocimiento sobre Frank Kafka, Sigmund Freud, Karl Marx, Eric Auerbach o Erwin Panofsky — reunidos coral y magistralmente en Contra la interpretación y otros ensayos - permiten entender que, si bien los historiadores no concurren en ese abanico, existe una preocupación por la interpretación del siglo $\mathrm{xx}$ a través de una historia intelectual.

Desde ahí, entonces, podemos preguntar apócrifamente ${ }^{2}$ sobre algunas discusiones historiográficas del siglo $\mathrm{xx}$ a partir de una autora que es una contramemoria historiográfica, pero que, al mismo tiempo, permite realizar un ejercicio de contrainterpretación de la historia de la historiografía del siglo xx. Y, más específico aún, proponer por qué una intelectual que no fue una lectora de historiadores, pero que sí sabía mucho de historia, nos ayuda para realizar esta contramemoria. Esta aseveración se fundamenta, específicamente, en cómo Susan Sontag en Contra la interpretación

1 "Prima di tutto, il sottotitolo: Machiavelli, Pascal. Perché la virgola? La virgola è un segno ambiguo: può indicare una congiunzione o una disgiunzione. In questo caso, entrambe. Nondimanco comincia sostenendo che Machiavelli imparò dalla casistica medievale a riflettere sulla norma e sull'eccezione, e finisce analizzando la feroce polemica di Pascal contro la casistica. Che cosa consente di pensare insieme Machiavelli e Pascal? (Ginzburg 11).

2 Las dos acepciones de "apócrifo" presentes en el Diccionario de la Real Academia: "falso o fingido" y "dicho de una obra, especialmente literaria: de dudosa autenticidad en cuanto al contenido o a la atribución”, no se acercan a la definición que utilizamos en este texto. Por "diálogos apócrifos" entendemos aquellos que no sucedieron efectivamente entre Sontag y la historiografía, pero que, en modo simultáneo, temporal y espacialmente, hay convergencias dialógicas producto de un determinado espíritu de los tiempos. 
da cuenta de procesos históricos mayores a partir de recorridos biográficos de los autores retratados en ese libro. Del mismo modo, al conocer la biografía de Sontag, ella siempre tuvo una especial atención por contextos y coyunturas que le ayudaban a repensar problemas estéticos. Por otra parte, en Sobre la fotografía la autora demuestra una conciencia histórica privilegiada, discutiendo la complejidad del tiempo pasado a través de la imagen. Asimismo, y desde las mismas ideas de la autora, hacemos una diferencia entre acontecimiento y momento, en la medida en que el primero refiere a un suceso importante que marca un antes y un después; mientras que momento designará no necesariamente un antes y un después, sino un instante en el tiempo.

La premisa anterior nos ayuda a entender algunas modificaciones epistemológicas y metodológicas del oficio de la historia. Sontag y su vocación ensayística anticipadora y diagnosticadora, con un impulso a mirar hacia delante, que detestaba la retrospectiva individual como ordenamiento intelectual, ${ }^{3}$ hace de esos diagnósticos intelectuales - como, por ejemplo, en "El antropólogo como héroe", dedicado a Levi-Strauss y su recepción en Estados Unidos (Sontag, Contra 95-110) - unos verdaderos coloquios apócrifos con paisajes historiográficos continentales y anglosajones en permanente cambio y tensión y, sobre todo, con formas de reflexión metodológica sobre la historia.

Ahora bien, teniendo en cuenta la premisa analítica precedente, es decir, entre la historia, los historiadores y Sontag existe una coma que es una conjunción y una disyunción al mismo tiempo, la pregunta que nos realizamos es ¿qué han aprendido los historiadores? Identificamos, en el modo de reflexionar de esta autora norteamericana, una analogía al trabajo del historiador en cuanto a clasificador de mujeres y hombres del pasado, tiempos, cronologías, documentos y escrituras. Esto, ciertamente, resulta vago y obvio, pues puede ser aplicado a cualquier disciplina o autor. En Susan Sontag, sin embargo, el problema de otorgarle un sentido al tiempo a partir de un mosaico de autores y de ofrecer un sistemático trabajo metodológico, es similar a las formas de clasificar del historiador.

Proponemos, entonces, que el marco cronológico entre 1966 —cuando publica Contra la interpretación - y 1977 — publicación de una recopilación de ensayos titulado Sobre la fotografía - permite entender y problematizar a Sontag como una historiadora a contraluz y a contrapelo de las discusiones al interior del llamado "giro cultural" historiográfico en Europa y Estados Unidos. ${ }^{4}$ Así, Sontag, historiadora — subrayamos la coma - es una forma de vincularla analíticamente con discusiones historiográficas,

3 Aunque lo hizo en la extensa entrevista a la revista Rolling Stone en 1978, ahora publicada en español completa en Jonathan Cott, Susan Sontag. La entrevista completa de Rolling Stone. Así expresa esa antipatía por la retrospectiva, en el epílogo, escrito en 1996, para la edición en español de Contra la interpretación: "Mirar en retrospectiva escritos de hace treinta años o más, no es un ejercicio saludable. Mi energía como escritora me impulsa hacia delante, a sentir que aún estoy empezando, en verdad empezando, ahora, lo que hace difícil contener mi impaciencia ante aquella escritora incipiente que una vez fui en sentido literal" (Sontag, Contra 387).

4 Aquí no podemos abordar la vasta literatura sobre el giro cultural de la historiografía desde los años 70 del siglo xx. Sin embargo, podemos citar algunos volúmenes que recorren en modo cronológico dichos cambios epistemológicos. Véase, sobre todo, Georg Iggers, Sonia Corcuera de Mancera y Peter Burke. En modo más analítico, y menos descriptivo, en François Hartog, Michel de Certeau y Arlette Farge. 
pero, al mismo tiempo, un modo de desvincularla metafóricamente de un mundo académico al que no pertenecía y pareciera ser que no le interesaba mayormente. ${ }^{5}$ Los autores que analiza y clasifica en Contra la interpretación se modelan como los documentos que le permiten ingresar al pasado para ordenarlo e interpretarlo, así como también su conceptualización de la memoria, a partir de las lecturas de imágenes en Sobre la fotografía, es una propuesta metodológica sobre cómo entender los vínculos entre memoria, imagen, realidad y que, hasta hoy, es un tema de vital actualidad en la historiografía. ${ }^{6}$

Pues bien, ahora podemos regresar a la pregunta: ¿Qué hemos aprendido de Susan Sontag? Para responderla realizaremos dos lecturas sobre la clasificación como problema fundamental de la historiografía y del oficio del historiador. En primer lugar, haremos una lectura historiográfica desde Contra la interpretación, insertando a la autora apócrifamente en el "giro cultural" de la historiografía, para luego abordar una lectura metodológica desde Sobre la fotografía. Ese término, "clasificación", que utilizamos a diario seleccionando fuentes, autores, escribiendo, haciendo clases, editando, en Sontag emerge como un paradigma de trabajo sistemático y una metodología con la que debemos, sin duda, aprender y dialogar. Sontag, a ratos, se nos presenta como historiadora, como clasificadora insaciable y furtiva de autores, imágenes y pasados, como el ogro de la fábula que huele la carne humana, como metaforiza Marc Bloch la búsqueda de lo humano en las fuentes, ${ }^{7}$ o bien, esa indestructible pesquisa del "sentimiento de la humanidad" como formulara Erwin Panofsky describiendo la muerte de Kant. ${ }^{8}$ Es a ella que presentaremos en las próximas páginas, a la que leemos como historiadores, pero que estuvo muy lejos de serlo. A ella que la une y la separa una coma de la historia y sus formas metodológicas.

5 Así lo expresa: "El cambio radical que había efectuado en mi propia vida, un cambio arraigado en mi traslado a Nueva York, era que ya no pensaba conformarme con ser una académica: montaría mi tienda fuera de la seductora, pétrea seguridad del mundo universitario" (Sontag, Contra 388).

6 Mientras redactamos este artículo la Cámara de Diputados del Congreso de Chile discute sobre una ley que condena el negacionismo de la dictadura militar. Ciertamente, las discusiones sobre los usos y abusos de la memoria comienzan a retornar al espacio público.

7 "El buen historiador se parece al ogro de la leyenda. Ahí donde olfatea carne humana, ahí sabe que está su presa" (Bloch 57).

8 “[...] recibió Immanuel Kant la visita del médico de cabecera. Enfermo, caduco y casi ciego, se incorporó al asiento y permaneció de pie, temblando de debilidad y murmurando a la vez algunas palabras ininteligibles. Tras unos instantes, su fiel compañero comprendió que solo se volvería a sentar hasta que él mismo lo hiciera. Solo entonces toleró Kant que lo acompañaran hasta el sillón que ocupaba. Una vez se hubo reestablecido, dijo esta frase: 'Das Gefühl für Humanität hat mich noch nicht verlassen' (No me ha abandonado aún el sentimiento de la humanidad)” (Panofsky 17). 


\section{“... La labor de interpretación lo es, virtualmente, de traducción"9}

Jorge Luis Borges murió el 14 de junio de 1986 en Ginebra. Diez años después, desde Nueva York, el 13 de junio de 1996, Susan Sontag escribió una carta a ese fantasma presente que la había rondado en su propia narrativa. El texto, publicado en el diario Clarín, es un gesto de epitafio, un reconocimiento intelectual, pero, al mismo tiempo, una carta de identificación emocional con un escritor respetado y admirado. Incluso, con su obsesión por la posteridad, Sontag se sentía identificada con Borges, y consolada al mismo tiempo, porque ambos no se habían ganado el Premio Nobel (Schreiber 323). Aquí, el inicio de esa carta, de ese fragmento de idolatría póstuma:

Dado que siempre situaron su literatura bajo el signo de la eternidad, no parece demasiado extraño dirigirle una carta. Si alguna vez un contemporáneo pareció destinado a la inmortalidad literaria, ese fue usted. Fue en gran medida el producto de su tiempo, de su cultura y, sin embargo, supo cómo trascender su tiempo, su cultura, de un modo que parece del todo milagroso. Esto tenía algo que ver con la amplitud y la generosidad de su atención. Fue el menos egocéntrico, el más transparente de los escritores, así como el más ingenioso. Algo tuvo que ver asimismo con una pureza natural de espíritu. Aunque vivió entre nosotros durante un tiempo más bien largo, perfeccionó las prácticas de la exigencia y la indiferencia que también lo convirtieron en un experto viajero mental a otras eras. Tuvo un sentido del tiempo diferente del de los demás. Las ideas comunes de pasado, presente y futuro parecían nimias bajo su mirada. A usted le gustaba decir que cada momento del tiempo contiene el pasado y el futuro, citando (según recuerdo) al poeta Browning, que escribió algo así como "el presente es el instante en el cual el futuro se derrumba en el pasado". Eso, por supuesto, era parte de su modestia: su gusto por encontrar sus ideas en las ideas de otros escritores. Esa modestia era parte de la seguridad de su presencia (Sontag, Cuestión).

No obstante, esa carta es más que eso. Nos quedaríamos cortos en la interpretación si pensamos que es solo un texto a otro escritor idolatrado. Sin duda hay una identificación emocional con Borges, pero también hay una identificación analítica con el trabajo del argentino. Si pudiéramos realizar una lista de los maestros de la clasificación del siglo xx, sin duda, estaría Borges junto a Raymond Queneau, Ítalo Calvino y Georges Perec. De

9 Creemos que la búsqueda de una nueva herméutica en Sontag se concentra en cómo entendía la interpretación y la traducción. Desde ahí deriva, por ejemplo, el uso de la preposición "contra" en el título de su recopilación de ensayos: "la labor de interpretación lo es, virtualmente, de traducción. El intérprete dice: 'Fíjate, ¿no ves que X es en realidad, o significa en realidad A? ¿Qué Y es en realidad B? ¿Qué Z es en realidad C?” (Sontag, Contra 16). 
estos autores, Sontag prefirió y eligió a Borges. La carta que Sontag dirige apócrifamente a Borges se encuentra en la colección de ensayos Cuestión de énfasis (2001), y el título es muy significativo. Ya al final de su vida, la norteamericana quería enfatizar en sus temas y en sus autores preferidos y, ciertamente, Borges, el clasificador, el ordenador de mundos fantasiosos e inconclusos, emerge con fuerza. Es el Borges de 1952, el de Otras inquisiciones, de ese extraordinario cuento sobre el curioso y polémico naturalista inglés del siglo XVII John Wilkins — que inspiró a Michel Foucault a escribir Las palabras y las cosas (1968) - que nos ofrece un indicio para comprender ese vértigo de las taxonomías e imposibilidades de clasificaciones en Sontag: "Notoriamente no hay clasificación del universo que no sea arbitraria y conjetural. La razón es muy simple: no sabemos qué cosa es el universo" (Borges 276). Sontag entendía sus clasificaciones como arbitrarias y conjeturales, tal como Wilkins y Borges, pero no menos verdaderas. Sus clasificaciones le consentían comprender el mundo, el pasado y los tiempos e intentar responder "qué cosa es el universo". Los hombres y las mujeres, reunidos en Contra la interpretación a partir de una historia intelectual del siglo xx, permiten a la ensayista clasificar y ordenar acontecimientos y, así, clasificar y ordenar su propio tiempo y biografía.

En esos múltiples gestos estereotipados de la literatura y, específicamente, de las máquinas editoriales, Carlos Fuentes, en la contraportada de la edición española del libro, se refiere a Contra la interpretación como ensayos que poseen "grandes interpretaciones, incluso acontecimientos, sobre lo que está sucediendo realmente". Fuentes, con ese gesto estereotipado, no se equivocaba. Los ensayos de Sontag son clasificaciones de acontecimientos a través de las trayectorias intelectuales de autores y obras de artes que se convierten en sus documentos de ingreso al pasado, pero también una comprensión del presente. El réquiem y canon infranqueable, sobre los vínculos inherentes entre el pasado y el presente, se hace carne, sujeto y verbo en los ensayos de Contra la interpretación a través de cómo clasifica y ordena temas, obras y autores en un sentido temporal.

Por ejemplo, una Sontag atenta a los problemas de la teorización y comprensión de un acontecimiento podemos observarla en el ensayo "Reflexiones sobre $E l$ Vicario". Polémica obra de teatro del dramaturgo alemán Rolf Hochhuth sobre las posibles omisiones de la Iglesia católica y, en particular, de Pío XII, sobre la Shoah. La norteamericana aborda el problema de los vínculos entre polémica y arte - la obra generaba disturbios en todas las ciudades europeas cuando se estrenaba-, sobre las elecciones individuales como martirio, pero, más importante aún, sobre lo que entendía por acontecimiento:

El mayor acontecimiento trágico de los tiempos modernos es el asesinato de seis millones de judíos europeos. En una época no carente de tragedias, tal suceso merece ese nada envidiable honor por razón de su magnitud, unidad de tema, significación histórica y absoluta opacidad. Porque nadie comprende este acontecimiento [...]. Este gran acontecimiento es una herida que nunca cicatrizará; incluso el bálsamo de la inteligibilidad nos es negado (Sontag, Contra 163) 
Un acontecimiento se define, para Sontag, por su magnitud, unidad, significación, opacidad y por su dificultad de comprensión e, incluso, se determina también por cómo ha sido seleccionado, clasificado y catalogado. El caso extremo de la Shoah, esa "historia desgarrada", como ha sido definida por Enzo Traverso (La historia desgarrada), hace de Contra la interpretación un manual de colección de acontecimientos a través de una interpretación de ideas literarias y filosóficas, así como de obras de arte. Las obras de arte, la producción intelectual, así, devienen en recuerdos históricos vinculados a acontecimientos que deben ser clasificados. Y el modo que tiene Sontag para sobrellevar el peso infalible de la infinidad de acontecimientos que observa, registra e intenta comprender (Shoah, guerra de Vietnam, fascismos, entre otros), es por medio de una "biografía coral"10 de autores que se despliegan, a veces en modo prosaico, y otras veces con elegante erudición.

Esa búsqueda clasificatoria de los acontecimientos que conocía y estudiaba pero que también experimentaba, a partir de las obras e ideas como recuerdo histórico, hizo que Sontag se anticipara a las discusiones historiográficas que se van a desplegar con intensidad en Europa en la década de 1970. El desprecio de la historiografía estructuralista — que tendrá como símbolo máximo a Fernand Braudel y sus tiempos históricos largos - de la histoire événementielle encuentra en Sontag un retorno refrescante. Como dice François Dosse, el acontecimiento nunca se ha ido pues siempre posee dos rostros: el de enigma (esfinge) y el de reinterpretación constante (fénix) (Renaissance). Es así como Pierre Nora, en 1974, declaró el retour de l'événement ("Le retour" 210-228), pero ya en 1966, había regresado, ciertamente con otros rostros a través de Sontag, solo que los historiadores no se habían percatado.

Su modo de entender su trabajo intelectual y de reflexión teórica por medio de la clasificación la convierte en una diagnosticadora y anticipadora apócrifa de la historiografía. Así como sucede con el acontecimiento, en Contra la interpretación, aquí encontramos la reflexión más articulada y estructural del libro, se vinculan constantemente las distinciones entre la circularidad de las culturas "alta" y "baja". Aunque no sabemos si lo leyó o no, eso había sido trabajado por el gran teórico ruso Mijail Bajtin en La cultura popular en la Edad Media y el Renacimiento. El contexto de François Rabelais, al analizar las trayectorias históricas del carnaval y las lecturas del libro Gargantúa y Pantagruel. Bajtin escribe su libro en 1941, pero su fortuna se

10 Una "biografía coral", como ha sido definida por Sabina Loriga al estudiar a los soldados en Piamonte en el siglo XVIII a través de una pluralidad de biografías (Soldats y Le petit), se contrapone al modelo de biografía clásica que genera una armonía entre "lo particular de la trayectoria y lo general del contexto", mientras que lo coral concibe "lo singular de la trayectoria como un elemento de tensión" (Dosse, El arte de la biografía 254). Lo coral enfatiza las múltiples trayectorias de experiencias, es decir, cada individuo considera la institución de manera diversa y posee significaciones heterogéneas de su realidad, de las lógicas colectivas e individuales, así como también existen distintos relatos de la experiencia de "estar en el mundo". La biografía coral, entonces, no pretende estudiar al individuo marcado por una misión, función o una virtud, sino que emplaza en esas trayectorias los conflictos, los padecimientos, lo heterogéneo, evitando, así, lo heroico. El individuo se mantiene plural y fragmentado para fisurar las homogeneidades (Levi). 
conseguirá con su traducción al inglés y al francés, precisamente en 1965, mientras Sontag redactaba sus ensayos, convirtiéndose en un volumen clave para que la historiografía tomara en cuenta esas distinciones, convergencias y divergencias entre lo "alto" y lo "bajo".

Sin embargo, la apertura teórica y vinculante con las formas "bajas" de cultura puede ser igual de intensa en la obra de Sontag y, sin duda, merece la pena abordarla historiográficamente, pues una vez más la norteamericana se anticipa a los historiadores o, para ser justos, dialoga apócrifamente. En su ensayo "Una cultura y una nueva sensibilidad", preocupada por la clasificación de las culturas en el arte contemporáneo, escribe:

La distinción entre cultura "alta" y "baja" (o de "masas" o "popular") está parcialmente basada en la evaluación de la diferencia entre objetos únicos y objetos de producción en masa. En una era de reproducción tecnológica en masa, la obra del artista serio tenía un valor especial, simplemente porque era única, porque llevaba su sello personal, individual. Las obras de la cultura popular (e incluso el cine fue durante largo tiempo incluido en esta categoría) fueron considerados de escaso valor por ser objetos fabricados en serie, que no llevaban un sello individual -elaboraciones de grupo hechas para un público indiferenciado-. Pero a la luz de la práctica contemporánea de las artes, esta distinción resulta extremadamente superficial (Sontag, Contra 377-378).

Mientras que la historiografía — desde diversos ángulos y perspectivas antropológicas, influenciada por las teorías del folklore y la oralidad, y enfocada a los problemas europeos de la primera Edad Moderna- comenzaba también a trabajar sobre los "desniveles" y la circularidad de las culturas. Ahí nos encontramos, desde la historiografía francesa, con Robert Mandrou y su extraordinario De la culture populaire aux XVIIe et XVIIIe siècles: la Bibliothèque bleue de Troyes 1 (1964), así como también con Emmanuel Le Roy Ladurie y Les paysans de Languedoc (1966). Desde el mundo anglosajón, la deuda con Primitive Rebels, de Eric Hobsbawn (1959), y el desciframiento de los carnavales de los Charivaris de Natalie Z. Davis (1971) y E. P. Thompson (1972) en Past and Present y Annales respectivamente, también se direccionaban hacia enfocar la cultura popular en un lente analítico más amplio. Este periodo de redefinición historiográfica y de incorporación de nuevos sujetos de estudios se verá condensado con Il formaggio e i vermi de Carlo Ginzburg (1976) que es, al mismo tiempo, un triunfo de la antropología de Clifford Geertz y su The Interpretation of Cultures (1973).

Si bien la preocupación de Sontag se dirige hacia el arte contemporáneo, participa y anticipa a un determinado espíritu de los tiempos historiográficos. El modo de reflexión clasificatorio y ordenamiento de las cosas del mundo es análogo a las metodologías puestas en práctica por historiadores en la década de 1960 y 1970 del siglo xx y que, ciertamente, no tenían en sus anteojeras a la norteamericana. El modo en que Sontag reflexiona sobre qué es un acontecimiento, o bien sobre los desniveles 
y niveles culturales son parte también de ese triunfo del "giro cultural" en el mundo intelectual y académico. Sontag es un fragmento de esas deudas teóricas que, con un cierto desfase temporal, aunque no aparezca mencionada, explicitó Lynn Hunt en The New Cultural History (1989) al reconocer en Antonio Gramsci, E. P. Thompson, Michel Foucault y Clifford Geertz las piezas claves del engranaje analítico cultural. Quizás, al analizar a Sontag y sus modos clasificatorios, ella también sería parte de ese engranaje, como otro intruso historiográfico, Siegfried Kracauer que muere el mismo año de la publicación de Contra la interpretación. Sus reflexiones históricas publicadas en modo póstumo, en 1969, en el magistral History: The Last Things Before the Last, al igual que Sontag, anticipan, participan y dialogan apócrifamente con la historiografía. Tal vez, es hora de integrarlos a las discusiones historiográficas, así como también a Sobre la fotografía que a continuación incluiremos en la conjunción y disyunción de la coma entre Sontag e historiadora.

\section{"Coleccionar fotografías es coleccionar el mundo"}

La frase que abre esta sección es una de las primeras ideas que aparecen en Sobre la fotografía (15). Susan Sontag tenía una fijación biográfica y analítica con el acto de recordar y con la memoria. Ambas fijaciones también tienen relación con otro de sus intereses: las colecciones. Irónicamente muchos de sus escritos han aparecido publicados en "colecciones de" cuentos, ensayos, etc.; textos agrupados por temática, enfoque, o aproximación. Si bien lo anterior no es necesariamente producto del esfuerzo o intención de Sontag, sino más bien una agrupación ejercida de forma externa por agentes literarios y editoriales, ella misma muchas veces hizo la selección. Quizás el caso más claro de lo anterior fueron los textos que escribió sobre imágenes y fotografía, publicados entre 1973 y 1977 en el New York Review of Books. Lo interesante de esta colección es que Sontag la ordenó, al menos cronológicamente.

En cierta medida, lo que Sontag propone en Sobre la fotografía es pensar en el rol que cumple este medio en nuestra vida cotidiana, pero también en la forma en cómo las fotos traducen nuestra percepción de la realidad. En este sentido, tanto la realidad como la fotografía están vinculadas a una cotidianeidad que es subjetiva y personal, al igual que la memoria. ${ }^{11}$

Para Sontag, la fotografía era el medio más realista y hacedero de las artes miméticas, ya que permitía fijar algo en el tiempo un momento específico, haciéndolo imborrable. Al mismo tiempo la fotografía se constituye como una versión inferior

11 Queremos aclarar que no nos haremos cargo de ideas sobre memoria colectiva, ya que nos parece un concepto problemático en sí mismo, y difícil de someter a una definición que funcione en tanto podríamos decir que la memoria colectiva se compone de todas las memorias personales reunidas. Sobre este punto inevitablemente pensamos en la obra de Alfredo Jaar La Geometría de la Conciencia (2009). 
pero ineludible de la realidad, idea que desarrolla sobre todo en "En la caverna de Platón” (Sontag, Sobre la fotografía 13-44). A través de seis ensayos la autora discute y dialoga con la obra de diferentes fotógrafos, todos quienes, de alguna forma u otra, y a través de su obra, la han invitado a mirar/observar y detenerse analíticamente en su trabajo fotográfico. La actividad que se realiza es el cuestionar cómo la realidad puede ser percibida y el conocimiento adquirido/ganado, situando sus preguntas dentro del contexto fotográfico de las imágenes mismas: la foto como herramienta, como industria, como actividad que delata una forma de ver (Berger 2008). De alguna forma lo que Sontag hace en su diálogo con la fotografía es tratar de entender cómo esta altera la realidad, registrando lo estéticamente placentero, en la medida que lo que se fotografía representa algo que llama la atención del fotógrafo, quien encuentra belleza en lo fotografiado.

Es aquí donde está la conexión con dos elementos que son vitales para quien estudia y hace historia: la colección y clasificación de imágenes, y el rol de la memoria. Todos estos elementos son relevantes cuando pensamos en la construcción de la narrativa histórica. De esta forma, la reflexión que guía el trabajo de Sontag, y el de esta sección, es el rol de la fotografía como objeto y el de nosotros como espectadores de estos objetos, y no de la fotografía en sí misma.

Un primer elemento para discutir tiene que ver con la materialidad de la imagen en relación con la historia. En su libro Sobre la fotografía Sontag sostiene "[1]as fotografías son, desde luego, artefactos" (103). En sus ensayos la intelectual reflexiona sobre el papel que la imagen técnica, como objeto moderno en sí mismo, cumple con las sensibilidades de la memoria. Una de las primeras observaciones de la autora tiene relación con la foto como una producción de la sociedad moderna. La invención de la fotografía, y su popularidad como práctica, van a permitir el desarrollo de cámaras cada vez más compactas, que podemos llevar con nosotros. Esto no solo habla de la relevancia que tienen las fotos en nuestra cotidianeidad sino de la capacidad técnica que implica esta evolución (LeMahieu, 1988). El impacto de la innovación tecnológica ayudó a generar el ambiente en que las imágenes están al centro de lo cotidiano, extendiendo el rol de lo visual. Lo anterior pone a la fotografía - como práctica y como acción - en el centro de las prácticas sociales, y por tanto a la imagen técnica como una experiencia de innovación tecnológica que se vive y tiene sentido porque es social. En este sentido, los usos cotidianos de prácticas modernas tendrán significados sociales y, por tanto, estarán llenas de significado.

Si bien la conexión con el trabajo de Walter Benjamin es indudable a lo largo de la compilación (y de su obra en general), se hace evidente cuando pensamos en el carácter serial de la foto y el hecho de que es un producto técnico, aunque no tan evidente como en la lista de citas que encontramos al final de Sobre la fotografía dedicada a W. B. En "La obra de arte en la era de la reproductibilidad técnica" la fotografía aparece como una de las artes menores que deben ser entendidas de forma de no ser subestimadas (Benjamin 211-244). Es la capacidad de reproducir una imagen 
mecánicamente lo que permite la liberación de la mano en la función artística, y la entrada de lo técnico en la reproducción de la realidad. Ahora, para Benjamin el gran problema de la reproducción técnica era la falta de presencia del tiempo y el espacio, lo que le quita su cualidad única. Lo interesante es que precisamente ahí en donde Benjamin sitúa la pérdida del aura es en donde otros intelectuales, como Sontag y Barthes, van a marcar la particularidad de la fotografía: su capacidad de reproducir un momento único que solo existe en esa fotografía y en ningún otro objeto/espacio/ tiempo. En otras palabras, esa autenticidad que se pierde para Benjamin es lo que dota a la fotografía de una de sus características más auténticas para Sontag: la capacidad mimética (capacidad a la que solo se llega producto de la técnica).

Para Roland Barthes, al igual que para Sontag, la fotografía es algo particular, un momento irrepetible. Ahora, el aspecto técnico que permite la producción en serie de esa imagen, pero no la reproducción del momento en sí mismo, es precisamente lo que Sontag vincula con la idea de las fotos como antigüedades instantáneas (Sontag, Sobre 118). En este sentido, la fotografía tiene la capacidad de transformar a un sujeto en objeto a través del acto fotográfico y de serializarlo. La cámara también dispara y atrapa. Quizás el mejor ejemplo de lo anterior eran las canchas de tiro fotográfico, un popular juego de parque de diversiones post Primera Guerra Mundial, en donde la persona que juega debía disparar al centro de un blanco, lo que disparaba una cámara que sacaba una fotografía de la persona disparando. ${ }^{12}$ Las canchas de tiro fotográfico jugaban con la idea de "disparar" o shoot una fotografía; o incluso la idea de que la cámara es capaz de atrapar el alma de quien es fotografiado. De dar en el blanco, lo que se lograba era un efecto en donde uno se disparaba a uno mismo, quedando una fotografía como prueba técnica y material del éxito de ese juego existencial. No es casualidad que este juego haya sido popular luego de la Primera Guerra Mundial, en donde la capacidad de lo técnico va a poner en cuestión su uso en términos de la capacidad de destrucción que tiene el ser humano. La fotografía, y en particular las canchas de tiro fotográfico, se presentaban como algo positivo, un encuentro de los dos mundos: entretención y destrucción. Esta dualidad se lee también en los ensayos sobre imagen de Sontag, en los que fotografía y muerte aparecen recurrentemente.

En este sentido, la fotografía se hace cargo de uno de los elementos que más ha fascinado al ser humano: el tiempo. La cámara, para Benjamin, separa al público de lo que fotografía, transportando la imagen, sacándola de contexto si se quiere. Lo que pasa entonces es uno de los trucos modernos más importantes, en tanto quien observa la fotografía se pone en el lugar de la máquina. En otras palabras, la identificación no se hace con quien hace la foto sino con la tecnología.

12 En noviembre de 2012, la Photographer's Gallery en Londres inauguró la exhibición “Shoot! Existencial Photography”, en la que se exploraban una serie de imágenes que eran el resultado de estas canchas de tiro fotográfico, así como experimentaciones de artistas usando la misma idea y técnica fotográfica. 
Volvamos sobre la idea de las fotos como antigüedades instantáneas que desarrolla Sontag. Walter Benjamin ofrece una entrada interesante a este punto. Benjamin fue quizás uno de los intelectuales que intentó definir la historia de manera más desesperada, en búsqueda de una forma de entender su presente. ${ }^{13}$ En sus "Tesis sobre la filosofía de la historia" (Benjamin 245-255), ofrece una definición del pasado que es muy fotográfica, al contrario de cómo se refiere a la fotografía y su relación con el tiempo en "La obra de arte en la era de la reproductibilidad técnica" (211-244). Benjamin señala que "Solo se puede medir el pasado como una imagen que destella, para nunca más verse, precisamente en el instante de su reconocimiento" (247). ${ }^{14}$ En esta cita Benjamin da cuenta de lo discutido anteriormente: la foto como un momento único, como un destello de un tiempo presente que se llena de materialidad a través de la fotografía como documento.

La conexión entre fotografía y momento a través de lo material da paso a una segunda idea a desarrollar: la relevancia que la clasificación juega en el trabajo de quien hace historia. Como al coleccionista, al fotógrafo lo anima una pasión que, si bien parece dedicada al presente, está vinculada a una percepción del pasado. Es decir, la pasión de un fotógrafo por un tema no tiene relación esencial con lo que lo hace clasificable. Lo interesante es pensar el rol que juegan las emociones y afectos en la relación con la fotografía. Para Benjamin, la capacidad de reproducir técnicamente generaba tal nivel de pérdida de lo íntimo, que la experiencia y la forma de relacionarnos con el arte cambiaba. De cierta manera, sostenemos que los ensayos sobre fotografía de Sontag prueban justamente lo contrario sobre la base del rol de atracción que tiene la fotografía en sí misma: lo estético y lo placentero como lo que logra restaurar la intimidad entre fotografía y audiencia. Es este vínculo lo que llena a la fotografía de significancia social. Esto tiene que ver con el hecho de que las imágenes reproducidas técnicamente han logrado enriquecer nuestro campo de percepción gracias al elemento tecnológico que está en el centro: la capacidad de mostrar cosas que no son fáciles de observar sin zoom, por ejemplo.

En relación con la historia como disciplina, el elemento temporal de la fotografía dialoga directamente con la labor de quien hace historia. Lo anterior ocurre no solo por el carácter documental de la fotografía como fuente histórica, sino por su capacidad de separar del espacio/tiempo un momento particular y transformarlo en objeto. El historiador, como el fotógrafo, en cierta medida es capaz de transformar espacios/tiempos determinados en libros-objetos, que al igual que la fotografía tienen una materialidad y pueden ser reproducidos técnicamente. Este contacto con la materialidad en la disciplina de la historia (las fuentes documentales cualquiera sea su medio y la producción de libros), es en donde el historiador muestra su verdadera 
identidad, la de coleccionistas (de datos, de documentos, de hechos, de conocimientos, de metodologías, de opciones, de libros, etc.). En cierta medida, quien hace historia es un constructor de colecciones. Respecto a lo anterior, Sontag va decir que la actitud del fotógrafo como la del coleccionista es asistemática, incluso antisistema (Sobre 115). En este punto no estamos del todo de acuerdo. Hay sistemas guiando al coleccionista y a la fotografía que son afectivos y personales y, por tanto, no del todo obvios a los demás. A continuación, reflexionaremos en torno a la importancia de la clasificación y el orden.

En la última sección/homenaje de Sobre la fotografía, Sontag selecciona una serie de citas relacionadas con la fotografía; conducta que imita las colecciones que Benjamin hacía de citas que llamaban su atención. Las citas que en el caso de Benjamin construirían el Libro de los pasajes son interpretadas por Sontag como verdaderas fotografías construidas con palabras (aunque dudamos si Benjamin estaría de acuerdo con esta apreciación). Esta colección de citas constituye también una lista de citas.

Una de las primeras cosas que se hacen al investigar es ordenar, decir, hacer listas materiales y mentales de archivos, de fuentes, de libros, de artículos, de ideas. A esto nos referimos cuando sostenemos que quien hace historia, clasifica. Esas listas, aunque no se cumplan al final, son vitales para estructurar el trabajo del historiador. Esto último es igualmente relevante al pensar en el trabajo que hace quien investiga en otras disciplinas: cualquiera sea el plan inicial, no es lo que se hace finalmente, y por lo demás, una enorme construcción de otras listas deviene de esas primeras listas. En este sentido, esa labor de clasificación y orden es un continuo pensar en nuevas formas de clasificar y ordenar nuevas ideas, que dan pie a nuevas listas, y así hasta que cerramos el proyecto y empezamos uno nuevo, con nuevas listas.

Parte de lo que explica la relevancia que tiene la manufactura de listas eternas son dos ideas: el rol que cumple la imaginación en lo que hace el historiador y el recordar. La imaginación es particularmente pertinente porque nos permite proyectarnos en el pasado. Volvemos entonces sobre la cita que mencionamos de Marc Bloch sobre el historiador como el ogro que olfatea lo humano en las fuentes históricas. Es decir, el historiador como coleccionista de la mortalidad, así como la fotografía para Sontag es una suerte de inventario de lo que ya no es, un memento mori (Sobre 32). La disciplina histórica no puede entenderse sin ese ejercicio de imaginación y búsqueda, de proyección de afectos en vidas ajenas, en tiempos pasados. Quien hace historia es un turista de lo pretérito, mientras que el fotógrafo es un turista de la realidad.

En el caso de Sontag, su búsqueda es más personal y se ve en particular en "Proyecto para un viaje a China" (1972) - que es parte de una colección de cuentos cortos, Yo, etcétera, publicada en 1977-, y que recuerda la misma coma propuesta por Ginzburg como un modo de conjunción y disyunción y que hemos aplicado en este artículo. En este trabajo Sontag imagina un viaje a China, su preparación, lo que hará ahí; pero también piensa en aquellas personas que han estado en China antes que ella, como Marco Polo, y sus padres. Quizás este es uno de los relatos más dolo- 
rosamente personales de Sontag y en donde entrega muchos detalles de su infancia. La autora cuenta cómo imaginaba China y cómo construyó el lugar "China” en su imaginación. La forma en cómo Sontag ordena su relato se lee también como una lista de ideas respecto de un nuevo lugar "China”, en la medida que ya no lo imagina desde su niñez, sino desde la adultez; imaginación que se llena de ideas de otros sobre China. Lo interesante sobre este ejercicio imaginativo que hace Sontag, que es nuevamente una suerte de diálogo apócrifo, es que da cuenta de la imposibilidad de la imaginación de llegar realmente al lugar imaginado. George Perec lo plantea de la siguiente manera:

Sin duda innúmeros pensadores y filósofos han disertado brillantemente a propósito de cosas sobre las cuales, al menos al principio, no tenían ningún conocimiento, pero aun así, pedir a un hombre que nunca usó gafas un ensayo sobre las gafas me parece, en principio, tan problemático como pedir a un hombre que jamás fue a la China una descripción de la China (Perec 142).

Inmediatamente después, Perec valida el ejercicio sosteniendo que el no saber le permite aproximarse al tema como un tercero. En cierta medida, lo que hace Perec, y el ejercicio de Sontag, es justamente validar la labor imaginativa del historiador.

Respecto al recordar, la digresión sobre China permite dar cuenta de la relevancia de lo personal en la forma en cómo nos aproximamos al tiempo no presente, tanto al futuro (un viaje que viene), pero sobre todo al pasado. Las colecciones fotográficas, ya sean colecciones curadas con cuidado o fotos reunidas asistemáticamente, tienen la capacidad de construir mundos y dar cuenta de ideas. Para Sontag, las fotos tienen la posibilidad de poseer la realidad y funcionan como un acceso instantáneo a lo real. Esto da cuenta de la segunda función que tienen las listas: ayudarnos a recordar; ${ }^{15}$ tal como Sontag aborda los autores en Contra la interpretación.

Las fotos, como material de investigación, tienen la virtud no solo de dar cuenta de un momento específico de la realidad, sino de una cierta cotidianidad. En cierta medida, quizás una de las fuentes más personales a las que podemos tener acceso es a fotografías, sobre todo pensando en el tema de las miradas que discute Roland Barthes al comienzo de su Camera Lucida, en donde al mirar un retrato a los ojos, uno se conecta con ojos que a su vez miraron a alguien más. Proponemos que las imágenes van inevitablemente de la mano con cómo entendemos la identidad, en la medida que quienes somos está inevitablemente amarrado a recuerdos. La memoria en sí misma tiene mecanismos internos (en muchos casos inconscientes) que pueden funcionar, tanto para mostrar como para ocultar. Cuando accedemos a la memoria también hay un desvelamiento que es fragmentario y muy subjetivo y, por lo mismo, es un ejercicio que está en permanente construcción. En cierta medida con la memoria

15 Recordar viene del latín recordari o re cordis, es decir, pasar de nuevo por el corazón. 
se da una suerte de simulacro, ya que no se trata de representar lo que existe, sino de expresar las tensiones entre lo actual como lo virtual y lo posible. Las fotografías también van a tener esta condición de simulacro. Lo que nos lleva a la última idea propuesta para la sección: el rol que la memoria juega en la aproximación de quien construye un relato historiográfico.

Quizás una forma de entender a Sontag en relación con la historia e historiografía es desde la clasificación que Pierre Nora ("Entre memoria”) hace entre memoria real e historia (que es como en el mundo moderno se organiza el pasado):

La memoria es la vida, siempre encarnada por grupos vivientes y, en ese sentido, está en evolución permanente, abierta a la dialéctica del recuerdo y de la amnesia, inconsciente de sus deformaciones sucesivas, vulnerable a todas las utilizaciones y manipulaciones, capaz de largas latencias y repentinas revitalizaciones. La historia, es la reconstrucción siempre problemática e incompleta de lo que ya no es. La memoria es un fenómeno perpetuamente actual, un lazo que nos amarra al eterno presente; la historia es la representación del pasado (20-21)

Hay un vínculo que nos amarra al presente, como en el caso de la temporalidad en las fotos; mientras que la historia es rearticulación del pasado, producción intelectual y secular, que conlleva análisis y criticismo. En este sentido, hay un ejercicio de actualización en la memoria que no existe en la historia: la necesidad de pasar de nuevo por el corazón.

Lo que queremos sugerir para terminar este apartado es que la imagen, y en particular la foto, constituye un espacio de memoria, es decir, un espacio en donde la memoria "se cristaliza y se refugia" (Nora, "Entre memoria" 19). A través de lo técnico se convierten experiencias en imágenes, las que son subjetivas y selectivas. En este sentido, el acto de clasificar imágenes está gobernado por lo que vale la pena ser reforzado en la creación constante de la memoria y de la identidad; por la relación de la fotografía con el tiempo y de la fotografía con quien la observa, con nuevos afectos y probablemente con una nueva lista que es parte de una nueva clasificación. Finalmente, la fotografía es un documento humano que no es solo un registro del pasado, sino una manera de tratar y relacionarse con el presente (Sontag, Sobre 233).

\section{Volver a la coma}

¿Es necesario preguntarse una vez más si esa coma, ese signo ambiguo declara en modo explícito esa conjunción o disyunción entre Sontag, la historia y la historiografía? Creemos que emplazar una coma entre Sontag e historiadora es distinto a declarar a Sontag como historiadora. Qué duda cabe, la ensayista norteamericana no fue una historiadora. Así que esa metáfora sería ingenua analíticamente e, incluso, falsa. Nuestra propuesta no se encamina en esa dirección. Lo que hemos realizado en 
este artículo es un ejercicio de lectura de Contra la interpretación y Sobre la fotografía para determinar convergencias y divergencias entre el modo de clasificar de la norteamericana y los modos de clasificación de los historiadores. No intentamos buscar una contigüidad analítica entre ambas formas de clasificar, sino delinear convergencias y divergencias en un cuadro temporal que permite conjeturar diálogos apócrifos entre Sontag y el giro cultural de la historiografía.

Esa lectura la hicimos a través del cuadro cronológico de 1966-1977, marcado por el giro cultural en la historiografía, y las publicaciones de los libros de Sontag analizados en este artículo. Esa cronología nos permite efectuar un emplazamiento temporal y espacial de los modos de reflexión de la norteamericana con las formas de hacer historia que se imponían con contundencia y sin contraposición en Europa y Estados Unidos. En ese sentido, analizamos Contra la interpretación como la clasificación de autores y una forma de ordenar el tiempo, la historia y su biografía y, por otro lado, Sobre la fotografía como una propuesta metodológica de ordenamiento y clasificación a través de los usos de las imágenes que modelan y construyen memorias. Es ahí donde encontramos que, en muchos casos, Sontag se anticipa y participa de un espíritu de los tiempos historiográficos.

Para concluir, podemos enfatizar una vez más que Sontag es una coleccionista de tiempos, mundos e imágenes, al igual que los historiadores. No obstante, debemos enfatizar, del mismo modo, que divergen y convergen en sus formas de cómo coleccionar. Y es ahí en donde Sontag se convierte en una intrusa para la historiografía, pero, sin duda, una ineludible intrusa que solo se separa o se vincula por un signo ambiguo, una coma.

\section{Referencias}

Barthes, Roland. Camera Lucida: Reflections on Photography. Nueva York, Hill and Wang, 2010.

Benjamin, Walter. Illuminations. Londres, Pimlico, 1999.

Berger, John. Ways of Seeing. Londres, Penguin, 2008.

Bloch, Marc. Apología para la historia o el oficio de historiador. México, Fondo de Cultura Económica, 2001.

Borges, Jorge Luis. Inquisiciones / Otras inquisiciones. México, De bolsillo, 2013.

Burke, Peter. La revolución historiográfica francesa: la escuela de los Annales: 19291989. Barcelona, Gedisa, 1994.

Certeau, Michel de. La escritura de la historia. México, Universidad Iberoamericana, 1993.

Corcuera de Mancera, Sonia. Voces y silencios en la historia. Siglos XIX y Xx. México, Fondo de Cultura Económica, 1997. 
Cott, Jonathan. Susan Sontag. La entrevista completa de Rolling Stone. Santiago, Ediciones UDP, 2014.

Dosse, François. El arte de la biografía. México, Universidad Iberoamericana, 2007.

- - Renaissance de lévénement. Un défi pour l'historien: entre sphinx et phénix. París, Puf, 2010.

Farge, Arlette. Lugares para la historia [1997]. Santiago, Ediciones UDP, 2008.

Ginzburg, Carlo. Nondimanco. Machiavelli, Pascal. Milán, Adelphi, 2018.

Hartog, François. Creer en la historia [2013]. Santiago, Ediciones Universidad Finis Terrae, 2014.

Iggers, Georg. La historiografía del siglo xx. Desde la objetividad científica al desafío posmoderno. Santiago, Fondo de Cultura Económica, 2012.

LeMahieu, D. L. A Culture for Democracy: Mass Communication and the Cultivated Mind in Britain between the Wars. Oxford, Nueva York, Clarendon Press, Oxford University Press, 1988.

Levi, Giovanni. "Les usages de la biographie". Annales, ESC, vol. 44, n 6, 1989, pp. 1325-1336.

Loriga, Sabina. Soldats. Un laboratoire disciplinaire: l'armée piémontaise au XVIII siècle. París, Les Belles Lettres, 2007.

-_. Le petit x. De la biographie à l'histoire. París, Seuil, 2010.

Nora, Pierre. "Le retour de lévénement", en Jacques Le Goff y Pierre Nora (dir.) Faire de l'histoire, 1. París, Gallimard, 1974, pp. 210-228.

- - . "Entre memoria e historia. La problemática de los lugares", en Pierre Nora, Pierre Nora en Les lieux de memoire. Montevideo, Trilce, 2008.

Panofsky, Erwin. "La historia del arte en cuanto disciplina humanística”. El significado de las artes visuales. Madrid, Alianza Editorial, 1979.

Perec, Georges. Pensar/Clasificar. Barcelona, Gedisa, 2007.

Schreiber, Daniel. Susan Sontag. Intelectualidad y glamour: una biografía. Santiago, Tajamar Editores, 2016.

Sontag, Susan. Yo, etcétera. Barcelona, Seix Barral, 1983.

-_. Sobre la fotografía. Buenos Aires, Alfaguara, 2006.

- - Cuestión de énfasis. Madrid, Alfaguara, 2007.

- - Contra la interpretación y otros ensayos. Buenos Aires, De bolsillo, 2008.

Traverso, Enzo. L'Histoire déchirée. Essai sur Auschwitz et les intellectuels. París, Éditions du Cerf, 1997. 